\title{
Cadmium chloride rapidly alters both BTB tight junction proteins and germ cells in young rat testes
}

\author{
Souad H. M. Bekheet
}

Zoology Department, Faculty of Science, South Valley University. Aswan, Egypt. E-Mail: shbekheet@yahoo.com

ABSTRACT

Intraperitoneal injections (ip) of cadmium chloride $\left(\mathrm{CdCl}_{2}\right)$ cause a marked and prolonged reduction of spermatogenesis, accompanied by increased permeability of the blood-testis barrier. Because the permeability of the blood-testis barrier is regulated by Sertoli cell tight junctions, and tight junction organization is regulated by the cytoskeleton, we undertook to examine the effects of $\mathrm{CdCl}_{2}$ treatment on intermediate filaments vemintin, and on the tight junction protein, occludin, adherens junction $\mathrm{N}-\mathrm{Cadhern}$ and gap junction connexin 43 in seminiferous tubules. Three weeks old rats received (ip) low or high dose ( $1 \mathrm{mg}$ or $2 \mathrm{mg} / \mathrm{kg}$ body weight) of either $\mathrm{CdCl}_{2}$ solution or saline (control) for 6 days. After injection, testes were collected and prepared for routine histology or whole seminiferous tubule Immunocytochemistry staining, and the preparations were viewed by light and electron microscopy for histopathology and fluorescence microscope for Immunocytochemistry studies.

The results indicate that cadmium exposure induces different degrees of histopathological alterations with both light and electron microscopy. Also, tight junction proteins occludin, N-cadherin and vimentin are all partially or completely disrupted by a cadmium injection. These results are consistent with cadmium-induced damage to rat testis as well as to tight junctions between adjacent intact cells. Perturbation of the tight junction-associated proteins could explain the increase in permeability of the blood-testis barrier observed after $\mathrm{CdCl}_{2}$ treatment. Impaired spermatogenesis following $\mathrm{CdCl}_{2}$ treatment is likely a consequence of a leaky blood testis barrier and disrupted Sertoli cell cytoskeleton. $\mathrm{CdCl}_{2}$ injections may serve as a useful tool in studying the relationship between cytoskeletal organization and the stabilization of Sertoli-Sertoli cell junctions. Suggesting that damage to Sertoli cell tight junctions induced by cadmium may be an underlying mechanism of their malemediated reproductive toxicity.

Keywords: Cadmium, Testes, Histopathology, Immunocytochemistry, Tight junction proteins, Rats.

\section{INTRODUCTION}

Most animals with scrotal testes are susceptible to cadmium-induced testicular toxicity (King et al., 1999). Although, only about 1-2\% of an acute cadmium dose is usually taken up by the testes, testicular toxicity is almost invariably evident. It has been reported that as low as $1-2 \mathrm{mg} \mathrm{Cd} / \mathrm{kg}$ body wt. can cause testicular damage without pathological changes to other organs (Prozialeck et al., 2006). Exposure to cadmium has been reported to reduce male fertility in both humans and rodents (Benoff et al., 2000). Although cadmium is a well known testicular toxicant, its mechanism of toxicity on this organ has not been completely elucidated. Among the proposed mechanisms for its toxicity on the testes: circulatory failure due to vascular 
damage and decreased utilization of $\mathrm{Zn}$ by spermatogenic cells due to competitive action of cadmium (Amara et al., 2008).

A major function of xenobiotic and endobiotic transporters is to move a wide range of organic substances across cell membranes. Sertoli cells play an important role in protecting developing germ cells by forming a physiological barrier, limiting exposure to potentially toxic substrates or conversely, facilitating uptake of xenobiotic within the testis (Augustine et al., 2005). At the base of the seminiferous tubules, tight junctions are established between neighboring Sertoli cells and form an integral part of the blood-testis barrier (BTB). This barrier divides the seminiferous epithelium into two compartments. The basal compartment and the adluminal compartment near the lumen of the tubule. Several integral or associated tight junction proteins have been identified in the testis including occludin (Furuse et al., 1993). The desmosome-like junction in the seminiferous epithelium was reported to possess the ultrastructural features of both the desmosome and gap junction (GJ) when examined by electron microscopy (Russell, 1977). There is accumulating evidence that desmosome can serve as a platform for signal transduction (Green and Simpson, 2007) and that connexin 43 (Cx43) can mediate cell-cell communication (Mese et al., 2007).

Gap junction intercellular communication plays an essential role in many physiological events including cell synchronization, proliferation, differentiation, apoptosis and metabolic coordination of vascular organs (Vinken et al., 2006; Mehta, 2007). A role of $\mathrm{Cx} 43$, the most ubiquitous $\mathrm{Cx}$, has been suggested in normal and pathological cell proliferation, but the mechanisms and the cellular effects may vary according to animals and cellular models (Pointis et al., 2007).

A normal organization of cytoskeleton components, specifically microfilaments and microtubules, is necessary for maintaining the integrity and proper functioning of these junctions (Hirsch and Noske, 1993). Cadmium induces disruption of actin microfilaments in Sertoli cells (Janecki et al., 1992; Hew et al., 1993).

More in vitro studies, however, suggest that the Sertoli cell is the most vulnerable target of $\mathrm{CdCl}_{2}$ and is more sensitive than Leydig cells to cadmiuminduced damage and an increase in BTB permeability, indicating a disruption of interSertoli tight junctions (Nancy et al., 2001). Studies by confocal microscopy illustrated that $\mathrm{CdCl}_{2}$ disrupted tight junction-associated microfilaments in rat Sertoli cells, which, in turn, damaged the BTB (Hew et al., 1993). $\mathrm{CdCl}_{2}$ also induced apoptosis in testicular tissue after ip injection (Xu et al., 1996). This event was characterized by an activation of endonuclease as a result of the loss of intracellular calcium (Lohmann and Beyersman, 1993). The $\mathrm{CdCl}_{2}$-induced damage of the inter-Sertoli tight junction permeability barrier was proposed as a model for toxicological investigations of the BTB in vitro (Janecki et al., 1992). This study was performed to investigate the cytotoxic effects of $\mathrm{Cd}$ on the testes and intratesticular cadmium treatment could serve as a non-hormonal tool for studying the role of the Sertoli cell tight junction cytoskeleton in spermatogenesis.

\section{MATERIALS AND METHODS}

\section{Experimental animals}

Male albino rats (Sprague-Dawley) 3 weeks old were used in this study. They were housed in a standard stainless steel cages maintained at controlled room temperature $\left(22^{\circ} \pm 2^{\circ} \mathrm{C}\right)$ for 12 hours light-dark cycle; standard pellet food and water were available ad-libitum. Animals were randomized into 3 experimental groups $(\mathrm{n}=$ 6) as follows: Group (I) animals received an (ip) of cadmium chloride in $0.9 \%$ saline 
at dose $1 \mathrm{mg} / \mathrm{kg}$ body weight (b.wt), group (II) animals were administered $2.0 \mathrm{mg}$ of $\mathrm{CdCl}_{2} / \mathrm{kg}$ b.wt, group (III) control group received equal volumes of vehicle. Animals were sacrificed by decapitation on the seventh day.

\section{Tissues preparation for histology}

\section{1- Light microscopy}

The testes from all experimental groups were removed and fixed immediately in Bouin's solution for 48 hours. The tissues were then placed in ethanol $70 \%$ for 24 hours, dehydrated, embedded in paraffin and sectioned at $5 \mu \mathrm{m}$, then stained with hematoxylin and eosin for evaluation of damage to seminiferous tubules with light microscope.

\section{2- Transmission electron microscopy}

Testes were immersed in $5 \%$ glutaraldehyde in $0.1 \mathrm{M}$ phosphate buffer at $4{ }^{\circ} \mathrm{C}$ for $3 \mathrm{~h}$ and post-fixed in $1 \%$ osmium tetraoxide. After dehydration in graduated series of ethanol, the tissues were embedded in epon 812. Blocks with tissues were cut into semithin sections, then stained with toluidine blue and examined using a light microscope. Representative fields of semithin sections were selected. Ultrathin sections were stained with uranyl acetate and lead citrate then examined with TEM.

\section{3- Immunofluorescent microscopy}

Fluorescent microscopy was used to assess damages to tight junction (TJs), adherent junction (AJs) and intermediate filaments at the BTB by co-localizations of occludin, $\mathrm{N}$-cadherin and vemintin, using testes from normal and $\mathrm{CdCl}_{2}$ treatment groups. Frozen sections of testes were fixed in Bouin's fixative, and nonspecific binding sites were blocked with $10 \%$ normal goat serum. In colocalization of occludin and $\mathrm{N}$-cadherin sections were incubated with a rabbit antioccludin antibody (1:100) followed by a goat antirabbit IgG-Cy-3. For N-cadherin staining, sections were incubated with a mouse anti-N-cadherin (1:100 Zymed laboratories), anticonnexin 43 (1:100) followed by a goat antimouse IgG-FITC. For vemintin staining, sections were incubated with a mouse anti-veminten (1:100 Transduction Laboratories) followed by a goat antimouse IgG-FITC Dako, Trappes, France. Sections were then washed, mounted in Vectashield Hardset with 4',6'-diamino-2phenylindole (DAPI) (Vector Laboratories, Burlingame, CA), and fluorescent microscopy was performed using an Olympus BX40 microscope equipped with Olympus UPlanF1 fluorescent optics. Slides incubated with normal rabbit antiserum were used as negative controls because immunoabsorption was not possible due to a lack of occludin, $\mathrm{N}$-cadherin, connexin 34 and vimentin antigens.

\section{RESULTS}

Prepubertal rats (21 day old) were chosen as the animal model since they are more sensitive to the reproductive toxicity (Richburg and Boekelheide, 1996). The sensitivity of young rats is attributed in part to differences in absorption, distribution, and metabolism between young and old rats (Heindel and Powell, 1992).

Exposure to cadmium chloride treatment induced no significant differences in both testes and body weight compared to control group.

\section{Testicular histopathology}

Histology was evaluated using cross sections of paraffin embedded testis stained with $\mathrm{H} \& \mathrm{E}$. Fig. 1 shows the histological alterations of the testes after low (1 $\mathrm{mg} / \mathrm{kg}$. body weight) or high $(2 \mathrm{mg} / \mathrm{kg}$. body weight $)$ dose $\mathrm{CdCl}_{2}$ administration for 6 days. Control group treated with saline showing normal testicular morphology and spermatogenesis, tubules lacking spermatocytes (Fig. 1a). In contrast, severe 
histological changes were observed in the testes of rats from the low-dose $\mathrm{CdCl}_{2}$ group, showed an extensive widening of the interstitial spaces. Moreover, some tubules showed complete necrosis and reduction of tubular lumen due to detachment and sloughing of spermatogenic cells. Since these detached spermatogenic cells lost the support and nurture provided by Sertoli cells, they can no longer survive and will eventually undergo apoptosis (Fig. 1b). At high dose $\mathrm{CdCl}_{2}$ group, in addition to the previous observations, the seminiferours tubules lost their typical architecture and a decrease of the intratubular tissue volume were seen. The testicular toxicity of $\mathrm{Cd}$ appeared to be mediated by a rapid apoptotic process as revealed by the increase numbers of pyknotic nuclei indicate apoptotic spermatogenic cells were distinctly observed in some seminiferous tubule (Fig. 1c).

Fig. 2 shows the transmission electron micrographs of the control normal Sertoli cell nucleus, spermatogonium, and spermatocyte (Fig. 2a) and $\mathrm{CdCl}_{2}$-treated rat testes (Figs. 2b, 2c). Sertoli cells with several vacuoles of different sizes and an increase in the density of cytoplasmic inclusions were seen at low dose group (Fig. 2b) as well as an apoptotic spermatogenic cell were distinctly observed at high dose group. An apoptotic cell is characterized by heterochromatin condensation and shrinkage of both cytoplasm and nucleus, and is surrounded by a normal Sertoli cell nucleus which is an indication of phagocytosis (Fig. 2c).

\section{Immunocytochemistry observations}

The immunocytochemical localizations of Sertoli cell junctional proteins (SCJP) (i.e., N-cadherin, oocludin, connexin 43 and vimentin) were determined in testicular sections obtained from control and exposed rats to $\mathrm{CdCl}_{2}(1 \mathrm{mg}$ or $2 \mathrm{mg} / \mathrm{kg} / \mathrm{day})$ (Figs. 3-5). The specific cells involved in the localization of these SCJP were found to be similar in both control and experimental groups; however, the intensity of localization differed significantly. Respective testicular sections incubated with normal preimmune mouse sera (negative controls) did not show any immunostaining. Using immunofluorescence analysis in cross sections of testes, after injection with low or high dose $\mathrm{CdCl}_{2}$ for 6 days, showed the basal lamina proteins expressed typical component of tight ( Occludin), anchoring (N-Cadherin), gap junction (connexin 43) and cytoskeleton intermediate filament (vimentin). Thus the majority of cadmium chloride tested, in addition to its disruption of spermatogenesis induced leakage of germ cell proteins from seminiferous tubules (STs) into interstitial fluid (IF); it effects on protein levels and was capable to delocalize the distribution of the three junctional proteins studied from membrane compartment such proteins have potential for use as biomarkers.

\section{Effects of cadmium chloride on occludin junctional proteins}

Fig. 3 shows the stage-specific expression of occludin in the seminiferous epithelium of control rat testes. Immunoreactive occludin was predominantly found near the basal compartment, consistent with its localization at the BTB. Occludin was expressed at high levels at the BTB during all stages of the seminiferous epithelial cycle, suggesting its importance in the maintenance of the BTB. Control occludin appeared to be localized to the cellular zone of the tunica propria, such as myoid cells and/or lymphatic endothelium, and the Leydig cells in the interstitium (Fig. 3a). Cadmium treatment affects the distribution and localization of basal lamina proteins. Sections of low dose cadmium-treated testes showed that occludin was generally absent in the basal regions of severely disrupted epithelia and was present in the apical regions of Sertoli cells or in peritubular cells (Fig. 3b). In high dose cadmiumtreated tubules, occludin levels were reduced in a dose - dependent manner. The decrease in protein levels associated with the disappearance of occludin associated 
with the disappearance of immunosignal from the membranous level at some places due to disruption of the close cell-cell (Fig. 3c).

\section{Effects of cadmium chloride on $\mathbf{N}$-cadherin junctional proteins}

Fig. 4 shows the stage-specific expression of $\mathrm{N}$-cadherin in the seminiferous epithelium of control rat testes. Like Occludin expressions, immunoreactive Ncadherin was predominantly found in all cells from spermatogonium to the lumen, consistent with its localization at the BTB. N-Cadherin was expressed at high levels at the BTB during all stages of the seminiferous epithelial cycle, suggesting its importance in the maintenance of the BTB (Fig. 4a). Cadmium treatment affects the distribution and localization of basal lamina proteins. Sections of low dose cadmiumtreated testes showed that $\mathrm{N}$-cadherin found at the lateral surface of epithelial cells, in areas of cell-cell contact. N-cadherin immunoreactivity was occasionally associated with interstitial cells and all germ cells were devoid of staining (Fig. 4b). Exposure to high dose cadmium chloride treatment induced obvious decrease in $\mathrm{N}$-cadherin levels, associated with the disappearance of immunosignal from the membranous level at some places due to disruption of the close cell-cell. No staining was detected in most germ cells and most of the interstitial areas were devoid of staining (Fig. 4c).

\section{Effect of cadmium chloride on intermediate filaments vimentin}

Vimentin was visualized by immunocytochemical staining. In Sertoli cells and germ cells from control rats, vimentin was seen surrounding the nucleus and extending apical extensions (Fig. 5a). Exposure to low dose cadmium chloride caused a dramatic loss in the staining of the apical vimentin extensions with a concomitant increase in the perinuclear staining intensity (Fig. 5b). Exposure to high dose $\mathrm{CdCl}_{2}$ exposure showed an intense in vimentin staining as seen in the nucleus (Fig. 5c), suggesting that vimentin filaments had collapsed towards both the Sertoli and germ cells nuclei in $\mathrm{CdCl}_{2}$ exposed animals. Cadmium chloride induced germ cells apoptosis was detected by the presence of pyknotic germ cell nuclei as observed with both light and electron microscopy. These results demonstrate that one of the early effects of $\mathrm{CdCl}_{2}$ is to interfere with the plasma membrane and to perturb its function, specifically its ability to establish cell-cell junctions that are essential for tissue homeostasis and control of cell proliferation and differentiation, such an alteration may play a specific role during carcinogenesis.

\section{Effects of $\mathrm{CdCl}_{2}$ on the gap junction protein connexin 43}

As Cx43 in Sertoli cells is believed to play an essential role in the control of spermatogenesis, we hypothesized that down regulated of this $\mathrm{Cx}$ may lead to an alteration of the blood-testis barrier function, providing a possible explanation for the impaired spermatogenesis. In control cells (Fig. 6a), a punctuate immunostaining for Cx43 along the plasma membrane of adjacent cells was observed in the control and treatment groups. The results showed that the expression of $\mathrm{Cx} 43$ at low and high doses $\mathrm{CdCl}_{2}$ exhibited decrease of the intensity of staining compared with that of the control group in dose-dependent manner (Figs. 6b, c).

\section{DISCUSSION}

The potential effects of $\mathrm{CdCl}_{2}$ exposure on male reproductive system and fertility have attracted public attention in recent years. A survey of published scientific literature indicated that exposure to $\mathrm{CdCl}_{2}$ could induce a large range of health problems including: dysfunction of $\mathrm{BTB}$, decrease the secretion of gonadotropic hormone $(\mathrm{GnRH})$, fertility, congenital malformations, prenatal death, intrauterine dysplasia; 
sexual dysfunction, abnormal embryonic development, etc. (Krichah et al., 2003, Atesi et al., 2004, Amara et al., 2008).

Our results also showed that acute $\mathrm{CdCl}_{2}$-administration produced marked histopathological alterations. Intoxicated with $\mathrm{Cd}$ chloride showed an extensive widening of the interstitial spaces, interstitial fibroplasias with a progressive sloughing of germ cells from the seminiferous epithelium were apparent in tubules lumen due to alteration of Sertoli cells and detachment of spermatogenic cells. Since these detached spermatogenic cells lost the support and nurture provided by Sertoli cells, they can no longer survive and will eventually undergo apoptosis. Also, alterations in Sertoli cells lead to a progressive degeneration of gonocytes which ultimately slough off into the tubular lumen. As shown with light microscopy, the testicular toxicity of $\mathrm{Cd}$ appeared to be mediated by a rapid apoptotic process as revealed by the increase of the number of apoptic germ cells nuclei in the seminiferous tubules of treated rats. The toxic effects of cadmium on testicular histology were dose-dependent. In the present finding, in transmission electron microscopy, apoptotic spermatogenic cells appeared to engulf by neighboring Sertoli cells. Sertoli cells play an important role in clearing apoptotic spermatogenic cells by the process of phagocytosis. It is likely to be a self-defense mechanism (Maeda et al., 2002). During spermatogenic cell differentiation, although more than half of differentiating spermatogenic cells die by apoptosis before they mature into spermatozoa (Dym, 1994). The apoptotic spermatogenic cells can be energy source for Sertoli cells to support spermatogenesis (Xiong et al., 2009). This observation agrees with other studies indicating the implication of apoptosis in the mechanism of cytotoxicity of Cd in testes (Krichah et al., 2003; Amara et al., 2008) and also in several organs of urogenital systems, including kidney, prostate, seminal vesicles and epididymis (Yan et al., 1997). Apoptosis is a highly regulated process that can be triggered by both exogenous and endogenous factors which can activate intercellular components such as caspases, AIF, cytochrome $\mathrm{C}$ leading to final condensation and fragmentation of the nucleus. Among the various subcellular organelles potentially involved in apoptosis, both lysosomes and mitochondria have been shown to send death signals through the activation of specific stress sensors (Ferri and Kroemer, 2001). Moreover, exposure to $\mathrm{Cd}$ induces oxidative DNA damage due to an excess of oxygenderived free radicals (Atesi et al., 2004). Our data suggests that metallothionein biosynthesis failed to protect DNA against the oxidative damage induced by $\mathrm{Cd}$ in the rat testis (Amara et al., 2008).

In chronic exposures to lower doses, the greater availability of metallothionein, bound to cadmium, means that the testicular lesion is less aggressive as compared to cases of acute intoxication (Waissmann, 2006).

Several mechanisms of Cd-induced testicular toxicity have been proposed. Lafuente et al. (2000) reported increased Cd accumulation in the hypothalamus, pituitary, and testis and decreased plasma levels of follicle stimulating hormone in rats, suggesting a possible effect of $\mathrm{Cd}$ on the hypothalamic-pituitary-testicular axis. Previous data also, suggests that reactive oxygen species (ROS) are involved in Cdinduced testicular damage (Oteiza et al., 1999). Acute, as well as chronic, Cd exposure is associated with elevated lipid peroxidation in the lung, brain, kidney, liver, erythrocytes, and testis (Bagchi et al., 1997).

In vitro studies, however, suggest that the Sertoli cell is the most vulnerable target of $\mathrm{CdCl}_{2}$ and is more sensitive than Leydig cells to cadmium-induced damage (Clough et al., 1990). In vivo injection of $\mathrm{CdCl} 2(30 \mathrm{ml} / \mathrm{kg} \mathrm{BW})$ to rats induced an increase in BTB permeability, indicating a disruption of inter-Sertoli TJs (Setchell and Waites, 1970). 
Studies by confocal microscopy illustrated that $\mathrm{CdCl}_{2}$ disrupted TJ-associated microfilaments in rat Sertoli cells, which, in turn, damaged the BTB (Hew et al., 1993). The $\mathrm{CdCl}_{2}$-induced damage of the inter-Sertoli TJ permeability barrier was proposed as a model for toxicological investigations of the BTB in vitro (Janecki et al., 1992).

Our study showed that $\mathrm{CdCl}_{2}$ disturbed the expression of more than one protein involved in cell adhesion (N-cadherin), and the formation of tight (occludin) and cytoskeleton intermediate filaments (vimentin) and gap junctions (connexin). Now, there is a strong evidence that these specialized junctional proteins are essential for the development and maintenance of spermatogenesis and that alterations of Sertoli-Sertoli cell or Sertoli-germ cell interactions may led to sterility in the male (Aumuller et al., 1992). Therefore, impaired Sertoli cell junctional protein expression seems to be sensitive and specific biomarker for cytoxicity studies in vivo. The expression of Occludin protein is detected via immunofluorescence in the testes of rats expressed at high levels at the BTB during all stages of the seminiferous epithelial cycle, suggesting its importance in the maintenance of the BTB. Occludin appeared to be localized to the cellular zone of the tunica propria, such as myoid cells and/or lymphatic endothelium, and the Leydig cells in the interstitium. Cadmium treatment affects the distribution and localization of occludin level is associated with decrease of occludin staining in a dose-dependent manner at the TJs which in turn leads to an increase in BTB permeability. Similar to our study, occludin immunostain is detected at all stages of the seminiferous epithelial cycle in dogs (Gye, 2004) and Korean wild rabbits (Yoon et al., 2009), in hamsters exposed to long-day photoperiods; the stage distribution was not reported (Tarulli et al., 2008). Interestingly, occludin is not expressed in the seminiferous tubules of guinea pigs (Cavia porcellus) and men (Moroi et al., 1998). These differences in occludin expression among species imply that the importance of occludin in regulating BTB integrity may be species-specific. Differences in the expression patterns among the rodent species may also be attributable to differences in antibody specificity among the antibodies used in the various studies (Ramos-Vara, 2005).

Studies performed by Fiorini et al. (2008) with ZO-1 and N-cadherin antibodies or in Cx43-GFP transfected cells showed that these junctional proteins were closely associated with vacuoles in SerW3 cells exposed to DDT. These observations support the idea that vacuoles induced by the chemical can reflect an exaggeration of the physiological internalization of junctional proteins. Constitutive endocytosis of adherens, tight and gap junctions have been shown in numerous epithelial remodeling processes (Matsuda et al., 2004). In the testis, junctional complexes located at the level of the blood-testis barrier between Sertoli cells are highly dynamic structures undergoing continuous remodeling. These junctions and their associated proteins are internalized by endocytosis and recycled to the new site of adhesion during translocation of germ cells from the basal to the adluminal compartment (Lui and Lee, 2006). Exaggerated internalization of junctional complex proteins has been shown in response to various pathologic stimuli (Ivanov et al., 2005).

In Sertoli cells of patients with impaired spermatogenesis, alteration of Cx43 expression has been suggested to be a marker of undifferentiated Sertoli cell functionality (Defamie et al., 2003; Altay et al., 2008). Thus, it has been postulated that altered Cx expression is a consequence of impaired testicular function rather than the cause of the testicular pathology. However, these data do not exclude the possibility that in response to environmental toxicants altered $\mathrm{Cx}$ expression may represent one mechanism responsible for the dysfunction of spermatogenesis, as 
suggested by in vitro findings (Fiorini et al., 2004, 2008; Zhou et al., 2008) and studies in rat and trout in vivo exposed to endocrine disrupting chemicals (de Montgolfier et al., 2008).

There are several ways by which toxicants can produce Sertoli cell dysfunction and testicular injury. Reproductive toxicants disturb apical cytoskeletal transport, induce microtubule-transport defects, alter germ cell attachment or decrease intercellular communication. This in turn will lead germ cell loss and disruption of the seminiferous epithelium. There is a growing list of environmental toxicants that appear to alter intercellular communication, such as dimet-acrylate, cadmium chloride (Cd), cisplatin, dichlorodiphenyltrichloroethane (DDT), dieldrin (DED), 1,3dinitrobenzene (DNB) and pentachlorophenol (PCP) can decrease gap junctional communication in cultured Sertoli cell (Fiorini et al., 2004). Since GJIC is important in normal cellular growth control, inhibition of intercellular communication of Sertoli cells by cadmium chloride may be an important mechanism of dysfunction of spermatogenesis. In the present research, the $\mathrm{Cx} 43$ expression decreased under the treatment of $\mathrm{CdCl}_{2}$ in a dose dependent. The results suggest that $\mathrm{CdCl}_{2}$ affected the GJIC by inhibiting the expression of $\mathrm{Cx} 43$ in seminiferous tubules, which may partially explain the mechanism of reproductive toxicity of $\mathrm{CdCl}_{2}$.

In the present study, the contribution of the collapse of Sertoli cell vimentin filaments to $\mathrm{CdCl}_{2}$-induced germ cell apoptosis needs to be explained. Vimentin filaments in the Sertoli cell are found both surrounding the nucleus and as apical extensions which radiate to the periphery of the cell where they associate with the plasma membrane in the region of attachment to germ cells. It has been proposed that these filament extensions are involved in maintaining the integrity of Sertoli cellgerm cell contacts (Aumuller et al., 1992). These observations are in agreement with our previous study (Bekheet and Stahlman, 2009) which showed that gentamicin impaired Sertoli-Sertoli cell direct interaction by altering junctional proteins levels (mainly occludin) or by inducing rapid cytoplasmic delocalization of these membranous protein, or by inducing cytoplasmic vacuolization (mainly vimentin), may be an early event of Sertoli cell injury (Fiorini et al., 2004). Also, DED, gossypol, $\mathrm{CdCl}_{2}$, Cisplatin or the mixed PDE3/4 inhibitor, Zardaverine which delocalized Zo-1, N-cadherin and CX43 from the membranes to the cytoplasmic compartment (Fiorini et al., 2004) or with other toxicants such as lindan, mono-(-2ethylhexyl) phthalate or cadmium induce cytoplasmic redistribution of Zo-1 and CX43 (Defamie et al., 2001). Also, studies by (Wiebe et al., 2000 ) using glyceroltreated rat testes have shown that the glycerol-induced disruption of inter-Sertoli TJs is associated with a dissolution of actin filaments and a loss of occludin staining at the TJs, which, in turn, leads to an increase in BTB permeability. These observations indicated the testicular toxicity exhibited by $\mathrm{CdCl}_{2}$. The changes in the distribution patterns of N-cadherin, ZO-1 and vimentine after $\mathrm{CdCl}_{2}$ exposure can be associated with the increased sloughing of germ cells. Thus, alterations in expression of SCJP complexes can be one of the possible mechanisms that lead to an induction of germ cell loss within the seminiferous epithelium, which causes impairments in spermatogenesis and fertility. Since $\mathrm{CdCl}_{2}$ in the present study and phthalate (Richburg and Boekelheide, 1996) cause alteration in expression of SCJP, it is tempting to suggest that expression of SCJP can serve as potent biomarker.

In conclusion, cadmium-induced loss of spermatogenic cells by apoptosis and ultrastructural changes in the Sertoli and spermatogenic cells cytoplasm. We observed that prepubertal administration of $\mathrm{CdCl}_{2}$ might have delayed the maturation of the seminiferous epithelium during spermatogenesis. Also, $\mathrm{CdCl}_{2}$ induced collapse in 
vimentin filaments may lead to alterations in germ cell apoptosis by a disruption in contact mediated communication between the Sertoli cells and germ cells. Consequently, intercellular junction proteins including occludin, $\mathrm{N}$-cadherin connexin 43 and vimentin are primary and sensitive targets for $\mathrm{CdCl}_{2}$ toxicity leads to an increase in BTB permeability. Suggesting that damage to Sertoli cell tight junctions induced by cadmium may be an underlying mechanism of their male-mediated reproductive toxicity.

\section{REFERENCES}

Altay, B.; Turna, B.; Oktem, G.; Aktug, H.; Semerci, B. and Bilir, A. ( 2008). Immuno-histochemical expression of connexin 43 and occludin in the rat testis after epididymal and vasal ligation. Fertil. Steril., 90: 141-147. (doi:10.1016/j.fertnstert.2007.05.065)

Amara, S.; Abdelmelek, H.; Garrel, C.; Guiraud, P.; Douki, T.; Ravanat, J.; Favier, A., Sakly, M. and Rhounia, K. B. (2008). Preventive effect of Zinc against cadmium - induced oxidative stress in rat testes. J. Reprod. Dev., 54 (2): 129-134.

Atesi, I.; Suzen, H.S.; Aydin, A. and Karakaya, A. (2004). The oxidative DNA base damage in testes of rats after intraperitoneal cadmium injection. Biometals, 17: 371-377.

Augustine, L.M.; Markelewicz, R.J.; Boekelheide Jr., K. and Cherrington, N. J. (2005). Xenobiotic and endobiotic transporter Mrna expression in the blood testis barrier. Drug Metab. Dispos., 33: 182-189.

Aumuller, G.; Schulze, C. and Viebahn, C. (1992). Intermediate filaments in Sertoli cells. Microsc. Res. Tech., 20: 50-72.

Bagchi, D.; Vuchetich, P.J.; Bagchi, M.; Hassoun, E. A.; Tran, M.X.; Trang, T. and Stohs, S. J. (1997). Induction of oxidative stress by chronic administration of sodium dichromate (cadmium II) to rats. Free Radical Biol Med, 22: 471- 478.

Bekheet S. H. M. and Stahlmann, R. (2009). Disruption of gap junctional intercellular communication by antibiotic gentamicin is associated with aberrant localization of occludin, N-cadherin, connexin 43, and vimentin in SerW3 Sertoli cells in vitro. Environmental Toxicology and Pharmacology, 28: 155-160.

Benoff, S.; Jacob, A. and Hurley, I. R. (2000). Male infertility and Environmental Exposure to Lead and Cadmium. Human Reprd. Update., 6: 107-121.

Clough, S. R.; Welsh, M.J.; Payne, A. H.; Brown, C. D. and Brabec, M. J. (1990). Primary Sertoli and interstitial cells exhibit a different response to cadmium. Cell Biol. Toxicol., 6: 63-79.

Defamie, N.; Mograbi, B. and Roger, C. (2001). Disruption of gap junctional intercellular communication by lindan is associated with aberrant localization of connexin 43 and zonula occludens-1 in 42GPA9 Sertoli cells. Carcinogenesis 22: $1537-1542$.

Defamie, N.; Berthaut, I.; Mograbi, B.; Chevallier, D.; Dadoune, J. P.; Fenichel, P.; Segretain, D. and Pointis, G. (2003). Impaired gap junction connexin 43 in Sertoli cells of patients with secretory azoospermia: a marker of undifferentiated Sertoli cells. Lab. Invest., 83: 449-456.

De Montgolfier, B.; Fournier, M.; Audet, C.; Marcogliese, D. J. and Cyr, D. G. (2008). Influence of municipal effluents on the expression of connexins in the brook trout (Salvelinus fontinalis) testis. Aquat. Toxicol., 86: $38-48$. 
(doi:10.1016/j.aquatox.2007.09.013) Dym, M., (1994). Spermatogonial stem cells of the testis. Proc. Natl. Acad. Sci., 91: 11287-11289.

Ferri, K. F. and Kroemer, G. (2001). Organelle-specific initiation of cell death pathway. Nat. cell Biol., 3: E255-E263.

Fiorini, C.; Tilloy-Ellul, A.; Chevalier, S.; Charuel, C. and Pointis, G. (2004). Sertoli cell junctional proteins as early targets for different classes of reproductive toxicants. Reprod. Toxicol., 18: 413- 421.

Fiorini, C.; Gilleron, J.; Carette, D.; Valette, A.; Tilloy-Ellul, A.; Chevalier, S.; Segretain, D. d and Pointis, G. (2008). Accelerated internalization of junctional membrane proteins (connexin 43, N-cadherin and Zo-1) within endocytic vacuoles: an early event of DDT carcinogenicity. Biochem. Biophys. Acta, 1778: 56-67.

Furuse, M.; Hirase, T.; Itoh, M.; Nagafuchi, A.; Yonemura, S. and Tsukita, S. (1993). Occludin: a novel integral membrane protein localizing at tight junctions. J. Cell Biol., 123:.1777-1788.

Green, K. J. and Simpson, C. L. (2007). Desmosomes: New perspectives on a classic. J. Invest. Dermatol., 127: 2499-2515.

Gye, M.C. (2004). Expression of occludin in canine testis and epididymis. Reprod. Domest. Anim.. 39: 43- 47. (doi:10.1046/j.1439-0531.2003.00474.x)

Heindel, J. J. and Powell, C. J. (1992). Phthalate ester effects on rat Sertoli cell function in vitro: Effects of phthalate side chain and age of animal. Toxicol. Appl. Pharmacol., 115: 116-123.

Hew, K.W.; Heath, G.L.; Jiwa, A. H. and Welsh, M. J. (1993). Cadmium in vivo causes disruption of tight junction-associated microfilaments in rat Sertoli cells. Biol. Reprod., 49: 840-849.

Hirsch, M. and Noske, W. (1993). The tight junction: structure and function. Micron., 24: $325-352$.

Ivanov, A.I.; Nusrat, A. and Parkos, C. A. (2005). Endocytosis of the apical junctional complex: mechanisms and possible roles in regulation of epithelial barriers. Bioessays, 27: 356-365.

Janecki, A.; Jakubowiak, A. and Steinberger, A. (1992). Effect of cadmium chloride on transepithelial electrical resistance of Sertoli cell monolayer in twocompartment cultures; a new model for toxicological investigations of the "blood testis" barrier in vitro. Toxicol. Appl. Pharmacol., 112: 51-57.

King, L. M.; Banks, A.W. and George, W. J. (1999). Differences in Cadmium Transport to the Testis, Epididymis and Brain in Cd-sensitive and Resistant Murine Strains 129/J and A/J 89. J. Pharmacol. Exp.Ther., 2: 825-830.

Krichah, R.; Ben Rhouma, K.; Hallègue, D.; Tébourbi, O.; Joulin, V.; Couton, D. and Sakly, M. (2003). Acute Cadmium Administration Induces Apoptosis in Rat Thymus and esticle, but not Liver. Polish Journal of Environmental Studies, 12(5): 589-594.

Lafuente, A.; Marquez, N.; Perez-Lorenzo, M.; Pazo, D. and Esquifino, A. I. (2000). Pubertal and postpubertal cadmium exposure differentially affects the hypothalamic-pituitary-testicular axis function in the rat. Food Chem Toxicol, 38: 913-923.

Lohmann, R. D. and Beyersman, D. (1993). Cadmium and zinc mediatd changes of the Ca21-dependent endonuclease in apotosis. Biochem. Biophys. Res. Commun., 190: 1097-1103. 
Lui, W.Y. and Lee, W.M. (2006). Regulation of junction dynamics in the estistranscriptional and post-translational regulations of cell junction proteins. Mol. Cell. Endocrinol., 250 : 25-35.

Maeda, Y.; Shiratsuchi, A.; Namiki, M. and Nakanishi, Y. (2002). Inhibition of sperm production in mice by annexin $\mathrm{V}$ microinjected into seminiferous tubules: possible etiology of phagocytic clearance of apoptotic spermatogenic cells and male infertility. Cell Death Differ., 9: 742-749.

Matsuda, M.; Kubo, A.; Furuse, M. and Tsukita, S. (2004). A peculiar internalization of claudins, tight junction-specific adhesion molecules, during the intercellular movement of epithelial cells. J. Cell Sci., 117: 1247-1257.

Mehta, P. (2007). Introduction: a tribute to cell-to-cell channels. J. Membrane Biol., 217: 5-12.

Mese, G.; Richard, G. and White, T. W. (2007). Gap junctions: Basic structure and function. J. Invest. Dermatol., 127: 2516-2524.

Moroi, S.; Saitou, M.; Fujimoto, K.; Sakakibara, A.; Furuse, M.; Yoshida, O. and Tsukita, S. (1998). Occludin is concentrated at tight junctions of mouse/rat but not human/ guinea pig Sertoli cells in testes. Am. J. Physiol., 274: C1708C1717.

Nancy, P.; Chung, Y. and Cheng, C. Y. (2001). Is Cadmium Chloride-Induced InterSertoli Tight Junction Permeability Barrier Disruption a Suitable in Vitro Model to Study the Events of Junction Disassembly during Spermatogenesis in the Rat Testis? Endocrinology, 142: 1878-1888.

Oteiza, P.I.; Adonaylo, V. N. and Keen, C. L. (1999). Cadmium-induced testes oxidative damage in rats can be influenced by dietary zinc intake. Toxicology, 137(1): 13-22.

Pointis, G.; Fiorini, C.; Gilleron, J.; Carette, D. and Segretain, D. (2007). Connexins as precocious markers and molecular targets for chemical and pharmacological agents in carcinogenesis. Curr. Med. Chem., 14: 2288-303.

Prozialeck, W. C.; Edwards, J. R.; Woods, J. M. (2006). The Vascular Endothelium as a Target of Cadmium Toxicity. Life Sci., 79(16): 1493-1506.

Ramos-Vara, J. A. (2005). Technical aspects of immunohistochemistry. Vet. Pathol., 42: 405-426. (doi:10.1354/vp.42-4-405)

Richburg, J. and Boekelheide, K. (1996). Mono-(2-ethylhexyl) Phthalate Rapidly Alters both Sertoli Cell Vimentin Filaments and Germ Cell Apoptosis in Young Rat Testes. Toxicology and Applied Phrmacology, 137: 42-50.

Russell, L. (1977). Desmosome-like junctions between Sertoli and germ cells in the rat testis. Am. J. Anat., 148: 301-312.

Setchell, B. P. and Waites, G.M.H. (1970). Changes in the permeability of the testicular capillaries and of the "blood-testis barrier" after injection of cadmium chloride in the rat. J. Endocrinol., 47: 81-86.

Tarulli, G.A.; Meachem, S. J.; Schlatt, S. and Stanton, P. G. (2008). Regulation of testicular tight junctions by gonadotrophins in the adult Djungarian hamster in vivo. Reproduction, 135: 867-877.

Vinken, M.; Vanhaecke, T.; Papeleu, P.; Snykers, S.; Henkens, T. and Rogiers, V. (2006). Connexins and their channels in cell growth and cell death. Cell Signal, 18: 592-600.

Waissmann, W. (2006). Occupational exposure and effects on the male reproductive system. Cad. Saúde Pública, Rio de Janeiro, 22(3): 485-493. 
Wiebe, J. P.; Kowalik, A.; Gallardi, R.L.; Egeler, O. and Clubb, B. H. (2000). Glycerol disrupts tight junction-associated actin microfilament, occludin, and microtubules in Sertoli cells. J. Androl., 21: 625-635.

Xiong, W.; Wang, H.; We, H.; Chen, Y. and Han, D. (2009). Apoptotic spermatogenic cells can be energy sources for Sertoli cells. Reprod., 137: 469-479.

Xu, C.; Johnson, J. E.; Singh, P. K.; Jones, M. M.; Yan, H. and Carter, C.E. (1996). In vivo studies of cadmium-induced apoptosis in testicular tissue of the rat and its modulation by a chelating agent. Toxicology, 107(1): 1-8.

Yan, H.; Cater, C.E.; Xu, C.; Singh, P.K.; Jones, M.M.; Johnson, J. E. and Dietrich, M.S. (1997). Cadmium-induced apoptosis in the urogenital organs of the male rat and its suppression by chelation. J. Toxicol. Environ. Health, 52: 149-168.

Yoon, S.I.; Park, C.J.; Nah, W.H. and Gye, M.C. (2009). Expression of occludin in testis and epididymis of wild rabbits, Lepus sinensis coreanus. Reprod. Domest. Anim., 44: 745-750. (doi:10.1111/j.1439-0531.2008.01064.x)

Zhou, D.R.; Zhou, Y.C.; Cui, G.H.; Guo, X.; Qin, J.; Gui, Y.T. and Cai, Z. M. (2008). Gossypol repressed the gap junctional intercellular communication between Sertoli cells by decreasing the expression of Connexin43. Toxicol. In Vitro, 22: 1719-1725. (doi:10.1016/j.tiv.2008.07.012) 

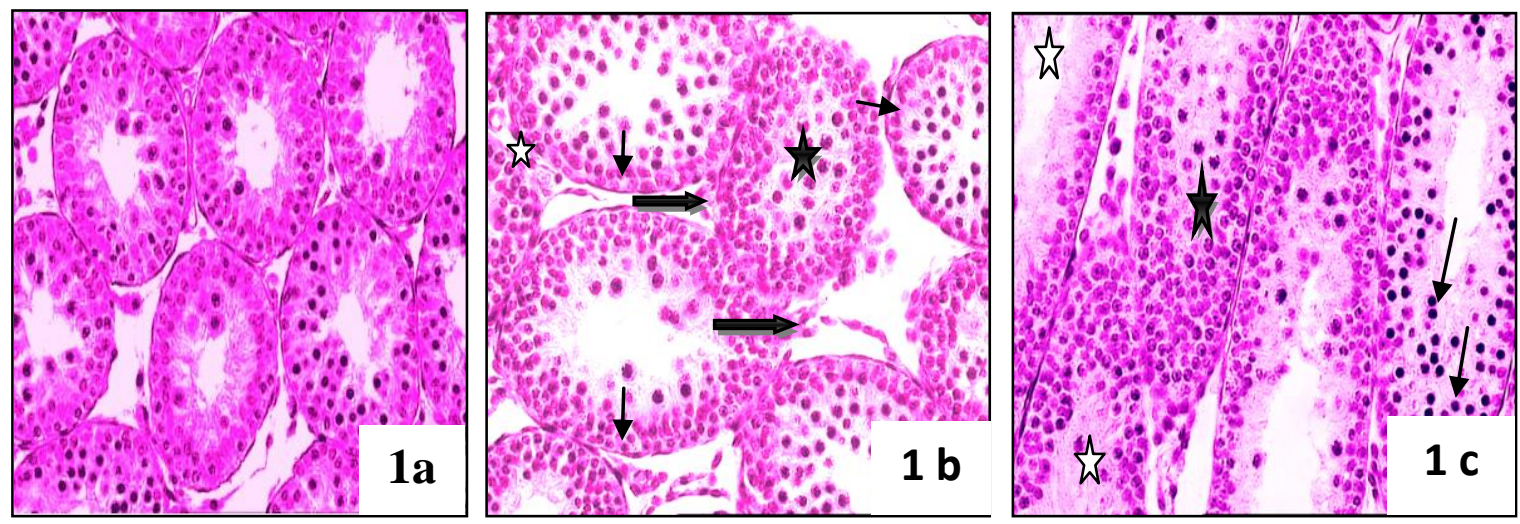

Fig. 1: Photographs of testicular sections of rat offspring exposed to cadmium chloride for 6 days in 21 days old rat. (1a) Testicular section of control animal treated with saline, notice typical seminiferous tubules morphology with multiple layer germ cells in various stages of development. (1b) Testicular section of exposed animal to $1 \mathrm{mg} \mathrm{CdCl}_{2}$ showing reduction of tubular lumen due to detachment and sloughing of spermatogenic (asterisk), vacuolization of Sertoli cell ( thin arrows) interstitial fibroplasia with mononuclear cells infiltrations (thick arrows). (1c) Testicular section of exposed animal to $2 \mathrm{mg} \mathrm{CdCl}_{2}$ showing disorganization of typical architecture of seminiferous tubules with a progressive sloughing of germ cells (black asterisk ), cellular debris and fibrins were apparent in tubules lumen (white asterisk), pyknotic nuclei indicate apoptotic spermatogenic cells were seen in some seminiferous tubules (thin arrows) H \& E. (400x) magnification.
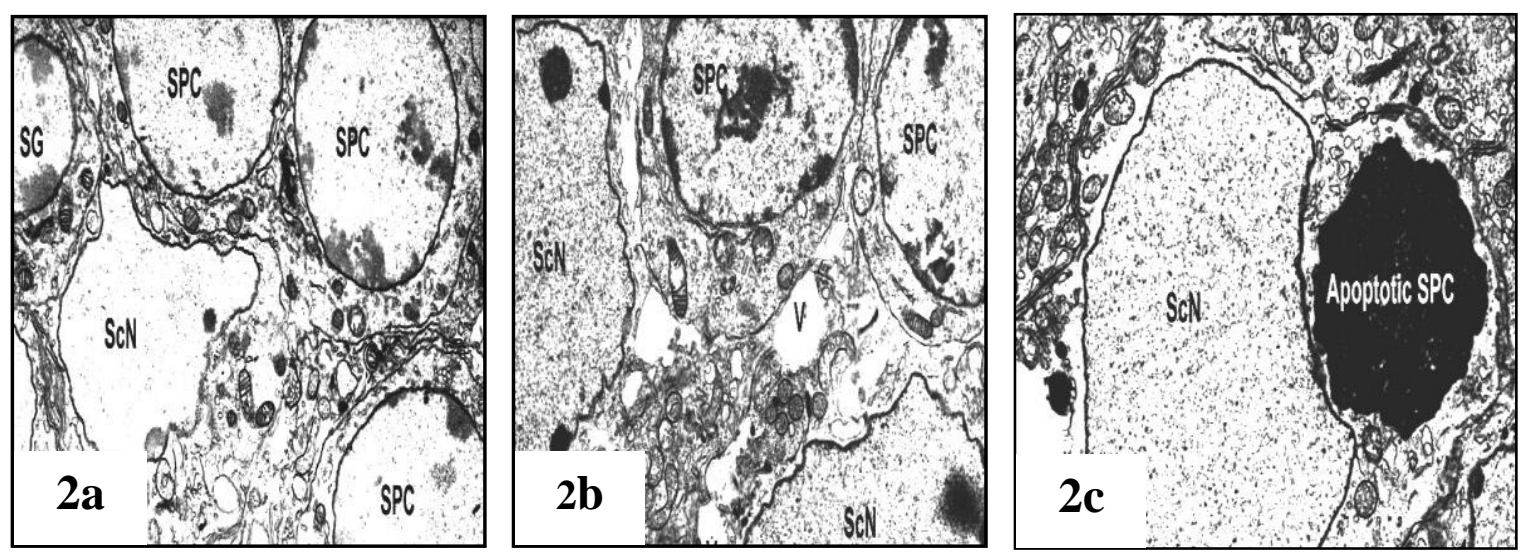

Fig. 2: Transmission electron micrographs of testes after single low or high dose cadmium chloride exposure at 21 day old rats. (2a) Control rats showing normal Sertoli cell nucleus $(\mathrm{ScN})$, spermatogonium (SG), and spermatocyte (SPC). (2b)Testicular section at $1 \mathrm{mg} \mathrm{CdCl}_{2}$ treatment showing the presence of vacuoles $(\mathrm{V})$ of variable sizes is distinctly observed in Sertoli cell. (2c) Testicular section at $2 \mathrm{mg} \mathrm{CdCl}_{2}$ treatment showing an apoptotic spermatogenic cell characterized by heterochromatin condensation and shrinkage of cytoplasm surrounded by a large phagocytic Sertoli cell nucleus. (Lead citrate and uranyl acetate X $5,400)$. 

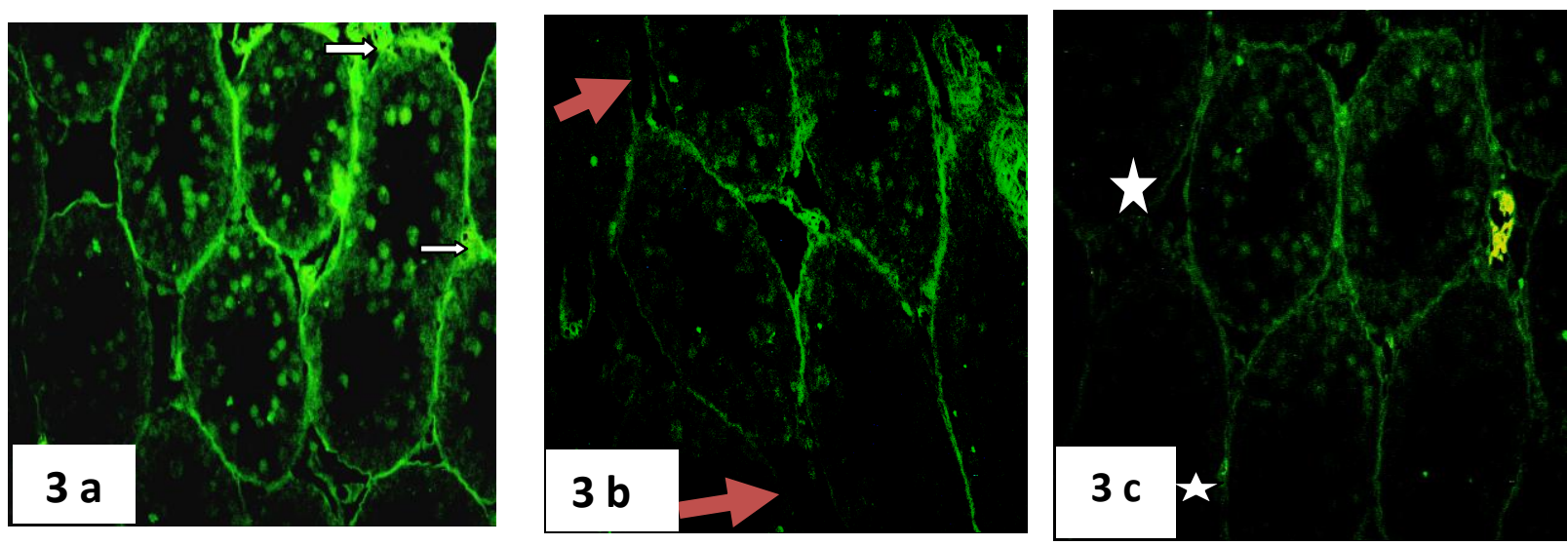

Fig. 3: Effect of low or high dose of cadmium chloride exposure on Occludin junctional proteins in 21 day old rat testis. (3a) Notice immunofluorescent localization of occludin in the seminiferous epithelium in testes from a control rat, Occludin was found to be localized at the basal compartment of the seminiferous epithelium consistent with its localization at the site of the blood-testis barrier, occludin appeared to be localized at the cellular zone of the germ cells, lymphatic endothelium, and the Leydig cells in the interstitium (thick arrows). (3b). In low dose $\mathrm{CdCl}_{2}$-notice a moderate decrease in the intensity of immunoreactivity occludin levels found to localize to the basal compartment of the seminiferous epithelium and completely disappeared in affected areas (red arrows). (3c) At high dose of $\mathrm{CdCl}_{2}$ exposure, showed high decrease in the intensity of immunoreactivity occludin levels in dose dependent manner (Astric). All magnifications 400x.
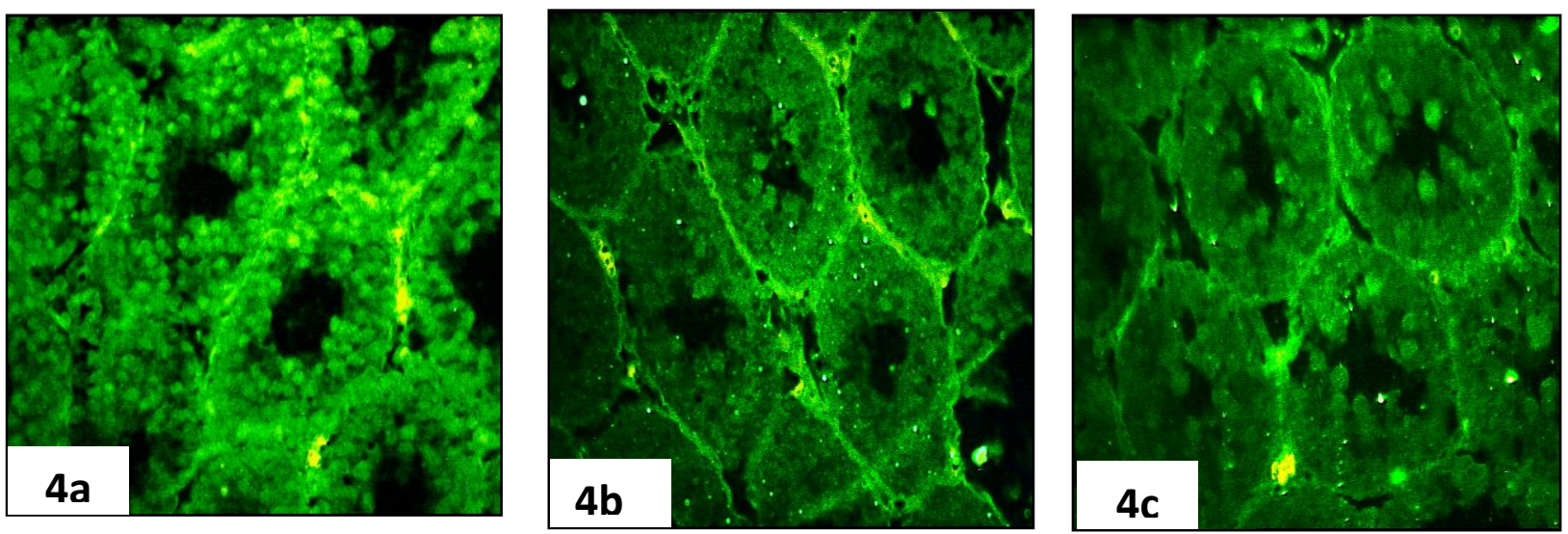

Fig. 4: Effect of low or high dose of cadmium chloride exposure on N-cadherin junctional proteins in 21-day-old rat testis. (4a) Notice immunoreactivity of $\mathrm{N}$-cadherin was associated with basally situated germ cells in the seminiferous tubules of control rat testis. (4b) At low dose $\mathrm{CdCl}_{2}$, strong N-cadherin reactivity was found at the lateral surface of epithelial cells, in areas of cellcell contact $\mathrm{N}$-cadherin immunoreactivity was occasionally associated with interstitial cells and all germ cells were devoid of staining. (4c) At high dose $\mathrm{CdCl}_{2}$, notice the decrease in the intensity of $\mathrm{N}$-Cadherin levels and no staining was detected in most germ cells and most of the interstitial areas were devoid of staining. $\mathrm{N}$ - cadherin levels were reduced in a dose-dependent manner. All magnifications 400x. 

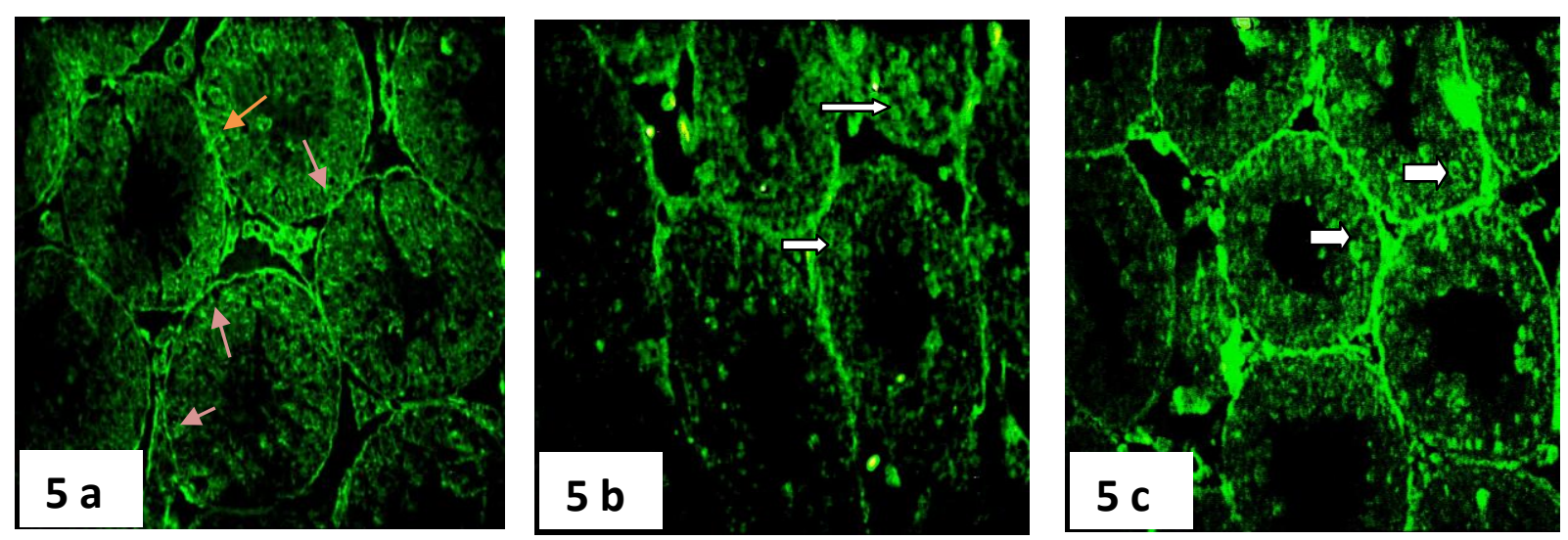

Fig. 5: Effects of low or high dose of $\mathrm{CdCl}_{2}$ exposure on vimentin filaments in 21-day-old rat testis. Vimentin was visualized by immunocytochemical staining. (5a) Typical seminiferous tubule expression of vimentin filaments in normal 21-day-old rat testis. Vimentin staining is seen radiating from the Sertoli cell perinuclear region with apical (arrows). (5b) At low dose $\mathrm{CdCl}_{2}$, notice many of the Sertoli cell vimentin apical extensions have collapsed. A dense vimentin filament staining is observed surrounding the nucleus (short arrows). (5c) At high dose $\mathrm{CdCl}_{2}$, a progressive increase in sloughing of the seminiferous epithelium is evident by detached germ cells (thick arrows). All magnifications 400x.
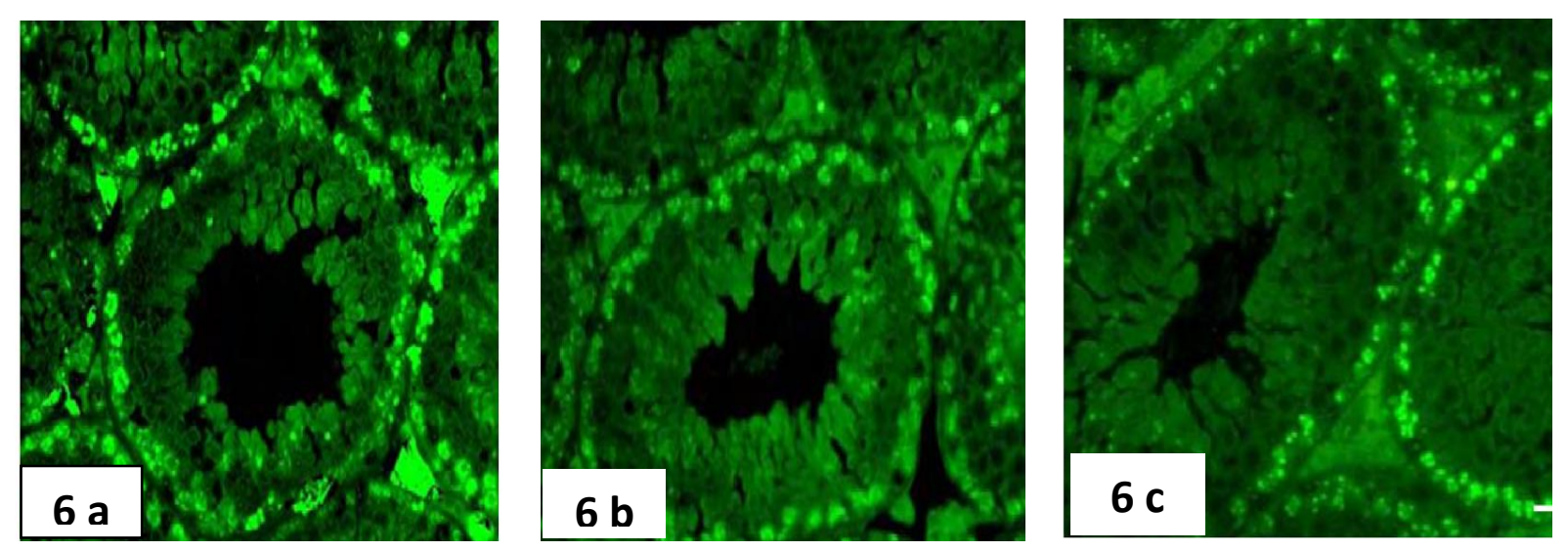

Fig. 6: Effect of low or high dose of cadmium chloride exposure on connexin 43 gap junctional proteins in 21-day-old rat testis. (6a). Notice immunoreactivity of connexin 43 was associated with basally situated germ cells in the seminiferous tubules of control rat testis. (6b) At low dose $\mathrm{CdCl}_{2}$, strong connexin 43 reactivity was found at the lateral surface of epithelial cells, in areas of cell-cell contact connexin 43 immunoreactivity was occasionally associated with interstitial cells and all germ cells were devoid of staining. (6c) At high dose $\mathrm{CdCl}_{2}$, notice the decrease in the intensity of connexin43 levels and no staining was detected in most germ cells and most of the interstitial areas were devoid of staining connexin43 levels were reduced in a dose-dependent manner. All magnifications 400x. 


\title{
ARABIC SUMMARY
}

\section{تأثير كلوريد الكادميوم على بروتينات الحاجز الدموى للخصية والخلايا الجرثومية فى الفئران غير البالغة}

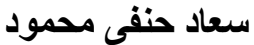

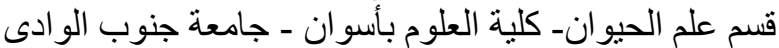

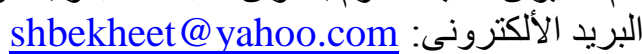

أدى حقن الغشاء البرينونى بكلوريد الكادميوم إلى انخفاض ملحوظ فى الخلايا الجرثومية مصحوبا

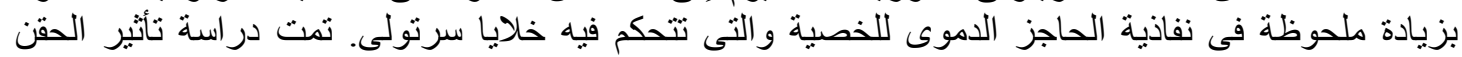

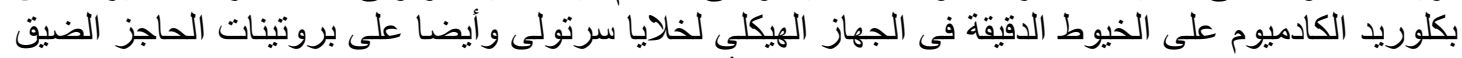

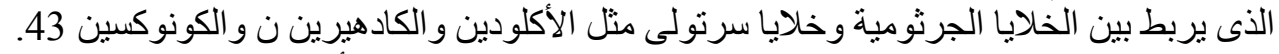

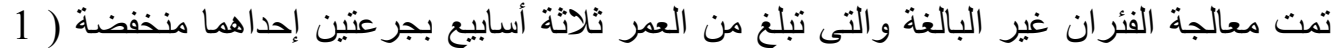

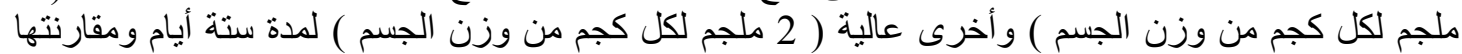

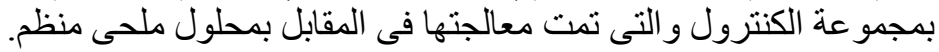

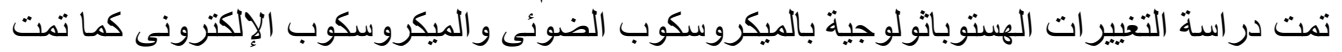

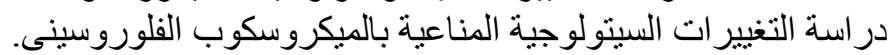

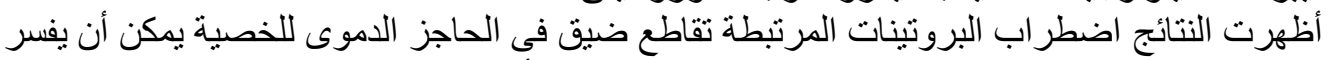

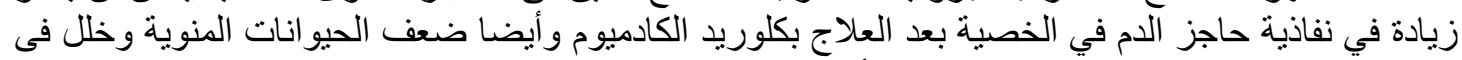

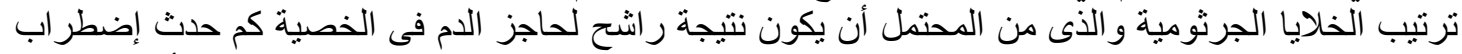

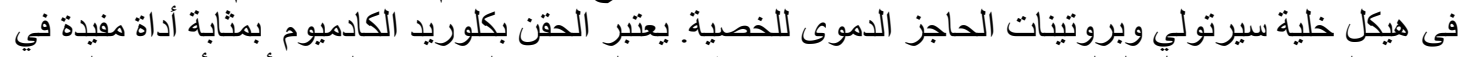

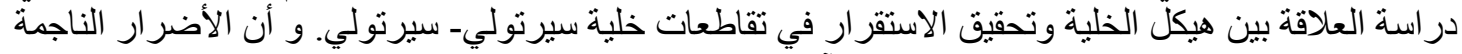

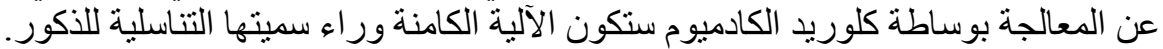

